\title{
Direct Electroless Copper Plating on Glass
}

\author{
Mitsuhiro WATANABE*, Hiroyuki SEIDA** and Hideo HONMA*,** \\ *Kanto Gakuin University Surface Engineering Research Institute(4-4-1, Ikeda-cho, Yokosuka-shi, Kanag- \\ awa 239-0806) \\ **Faculty of Engineering, Kanto Gakuin University(1-50-1, Mutsuura-Higashi, Kanazawa-ku, Yokohama- \\ shi, Kanagawa 236-8501)
}

\begin{abstract}
Direct copper deposition on glass without etching is difficult to obtain by the conventional electroless copper treatment process. The formation of copper films on glass without exfoliation of copper from the glass substrate can be accomplished by introducing an alcohol treatment after the conventional sensitization and activation steps. This was followed by the electroless copper deposition.

Adhesion strength was improved by heat treatment under an inert atmosphere. Furthermore, copper circuit patterns with widths of 4 to $6 \mu \mathrm{m}$ were formed by the semi-additive process.
\end{abstract}

Keywords : Electroless Copper Plating, Glass Substrate, Pattern Formation

\section{Introduction}

The glass substrate is available with large area, low cost, and smooth surface, which simplifies device processing. The different types of glass are used as the substrates for electronic displays, optical fibers, thick-film packaging and other electronic equipments.

In this paper, we discuss the preparation of direct copper deposition on glass. If copper is deposited directly on glass without etching, high speed propagation especially for high frequency signals can be achieved. Direct copper deposition on glass has not been achieved by the conventional electroless copper treatment process. We succeeded to form electroless copper films on glass without exfoliation and to improve its adhesion by introducing an alcohol dip and by heat treatment.

\section{Experimental}

In this experiment, $26 \times 38 \mathrm{~mm}$ micro slide glass (Matsunami Glass Ind. Ltd.) was used as the sample substrate. The glass substrate was treated with sensitization and activation treatment for three times after an initial ultrasonic rinse in D. I. water. This was followed by a methanol dip for 1 minute at room temperature. Standard electroless plating was then carried out. Surface morphologies, before and after electroless plating, (thickness, ca, $0.2 \mu \mathrm{m}$ ) were observed with an Atomic Force Micrograph (AFM) (Shimadzu Corporation, SPM-95300 J 3). Adhesion was tested using a peel test with cellophane tape. The pretreatment process, composition of electroless copper bath and the operating conditions are shown in Table 1 and 2 .

\section{Results and Discussion}

Our previous research showed that exfoliation of the copper films from the glass was observed during plating ${ }^{2)}$ using the standard electroless plating process. However, we succeeded in the electroless deposition of copper without exfoliation by decreasing the concentration, as conventional electroless copper composition, as shown in Table 2. However, many blisters were observed after electroless copper plating when a

Table 1 Experimental procedure.

\begin{tabular}{lr}
\hline Copper (II) Sulfate Pentahydrate & $0.006 \sim 0.03 \mathrm{~mol} / \mathrm{dm}^{3}$ \\
EDTA Tetrapotassium & $0.089 \sim 0.384 \mathrm{~mol} / \mathrm{dm}^{3}$ \\
2,2 -Bipyridyl & $0.1 \mathrm{~g} / \mathrm{dm}^{3}$ \\
PEG-1000 & $0.1 \sim 5.0 \mathrm{~g} / \mathrm{dm}^{3}$ \\
Formaldehyde & $0.05 \sim 0.2 \mathrm{~mol} / \mathrm{dm}^{3}$ \\
\hline pH & $11.5 \sim 12.5$ \\
Temp. $\left({ }^{\circ} \mathrm{C}\right)$ & 60 \\
Agitation & None \\
\hline
\end{tabular}

Table 2 Electroless Cu Plating Bath Composition and Conditions.

\begin{tabular}{|c|c|c|c|}
\hline $\begin{array}{l}\text { Ultrasonic cleaning } \\
\nabla\end{array}$ & & R. T & 5 min. \\
\hline $\begin{array}{c}\text { Alkaline degreasing } \\
\nabla\end{array}$ & & $60^{\circ} \mathrm{C}$ & 5 min. \\
\hline $\begin{array}{c}\text { Acid dipping } \\
\nabla\end{array}$ & & R. T & $1 \mathrm{~min}$. \\
\hline $\begin{array}{c}\text { Sensitization } \longleftarrow \\
\nabla\end{array}$ & $\times 3$ & R. T & $1 \mathrm{~min}$. \\
\hline $\begin{array}{l}\text { Activation } \\
\qquad \nabla\end{array}$ & & R. T & $1 \mathrm{~min}$. \\
\hline $\begin{array}{l}\text { Methanol dipping } \\
\nabla\end{array}$ & & R. T & $1 \mathrm{~min}$. \\
\hline Electroless $\mathrm{Cu}$ platin & & $60^{\circ} \mathrm{C}$ & $10 \mathrm{~min}$. \\
\hline
\end{tabular}


conventional pretreatment was used. About $0.2 \mu \mathrm{m}$ of uniform copper film without blisters could be obtained by introducing a methanol dip, after the sensitization and activation step cycle.

We observed the morphology of the deposited copper using AFM. Many nodules were observed on the glass surface after the activation treatment using the standard pretreatment as shown in Fig. 1(a), and they increased in size following after the electroless copper plating as shown in Fig. 1(b). On the other hand, these nodules could be suppressed by introducing a methanol dip, after the Pd activation step. As can be seen in Fig. 1(c), by introducing the methanol treatment, the catalyst was distributed uniformly on the glass substrate due to the suppression of Pd agglomeration. As a result, the $\mathrm{Cu}$ film was deposited uniformly without any blisters after plating, as shown in Fig. 1(d).

The adhesion of the deposited copper was measured by a peel test using cellophane tape. Copper was easily detached from the glass right after plating. (Fig. 2(a)) However, adhesion improved with time and finally only few spots were delaminated from the glass after $24 \mathrm{hrs}$ at room temperature. (Humidity not controlled) (Fig. 2(b))

Improvement of adhesion might be due to the escape of the hydrogen from the deposited copper films. Therefore, we tried to improve the adhesion a)
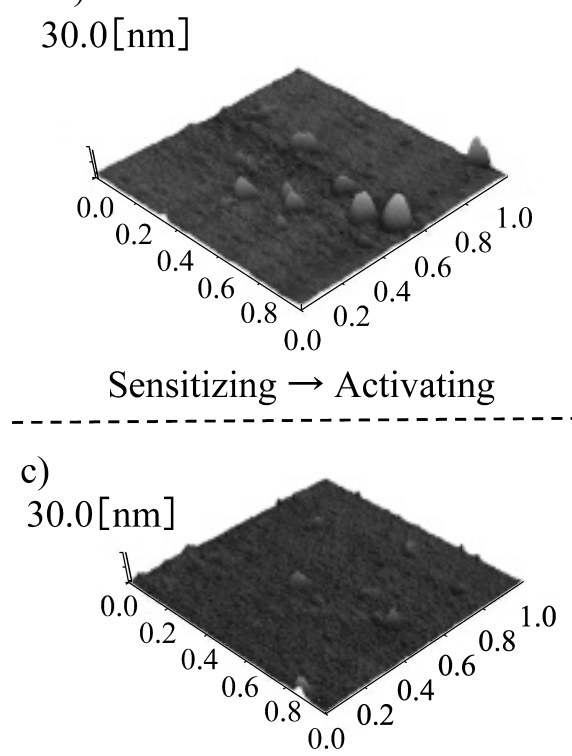

Sensitizing $\rightarrow$ Activating $\rightarrow$ methanol dipping b)

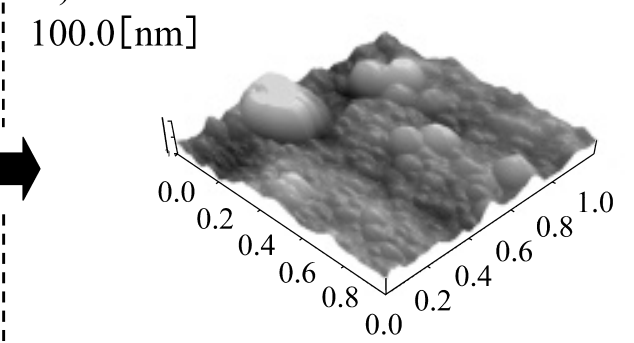

After Electroless Copper Plating

d)

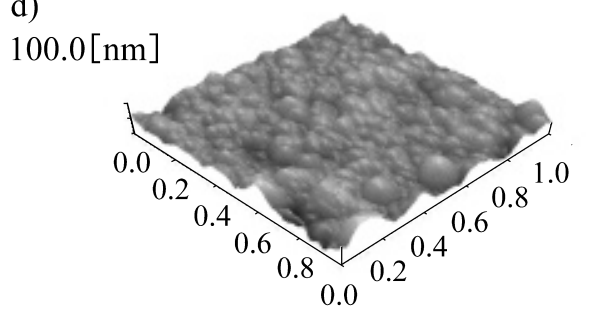

After Electroless Copper Plating

Fig. 1 Morphologies of Deposited Copper on Glass Substrate.

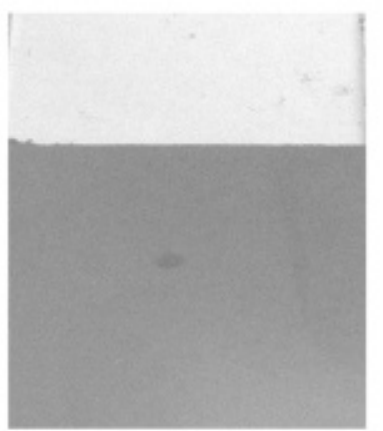

(a)

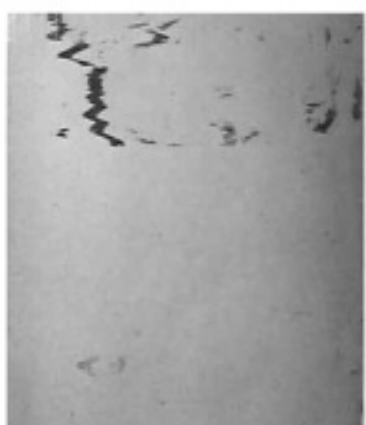

(b)

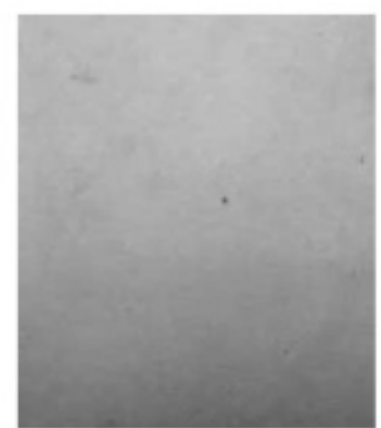

(c)

$10 \mathrm{~mm}$

Fig. 2 Evaluation of Adhesion by Cellophane Tape

The upper one-third was measured

a) As plated. Deposited copper was detached from glass

b) After standing for $24 \mathrm{hrs}$. Some parts of deposited copper were detached from glass

c) After heat treatment. Deposited copper was remained on the glass 


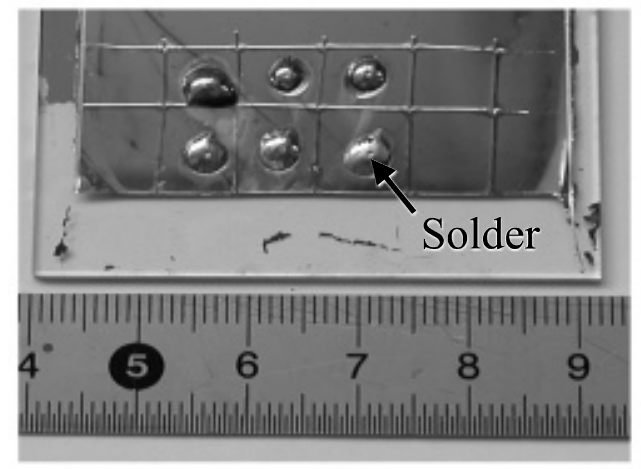

(a)

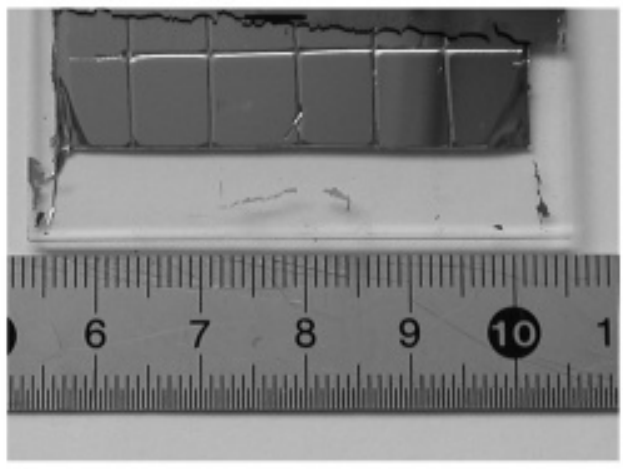

(b)

Fig. 3 Solder Resistance Test.

a) Top view after soldering b) Back side view

No separation between deposited copper and glass after scratch test.

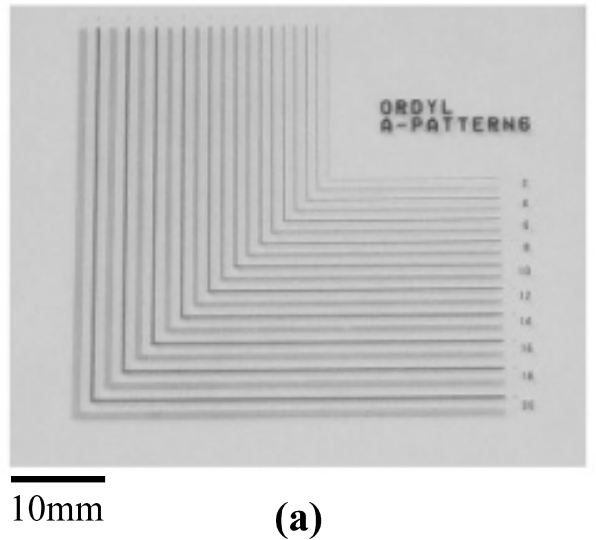

(a)

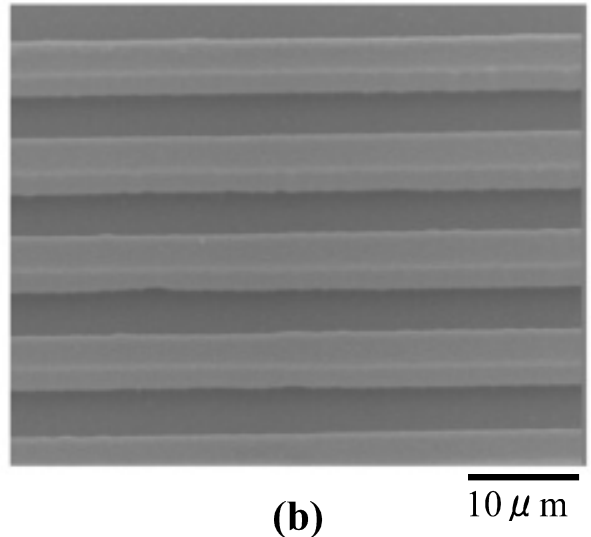

(b)

Fig. 4 Copper Wiring Pattern Images by Semi-additive Process. a) Visual image, b) SEM image

by introducing a heat treatment step ${ }^{3)}$. After heat treatment at $300^{\circ} \mathrm{C}$ for 60 minutes, under an inert atmosphere, the deposited copper was not removed from the glass by the cellophane tape, as can be seen in Fig. 2(c).

To measure the adhesion strength after soldering, about $5 \mu \mathrm{m}$ of copper was deposited by electroplating after the electroless copper plating. Solder spots were formed from hot solder at $350^{\circ} \mathrm{C}$ for 5 seconds. Solder did not detached from the deposited copper after doing a scratch test (JIS) as shown in Fig. 3.

The formation of copper wiring patterns was evaluated by a semi-additive process. Photo resist (TOK, PC-0059 B PM) was used to produce wiring patterns. The resist patterns are composed of $10 \mu \mathrm{m}$ thick test patterns, 2 to $20 \mu \mathrm{m}$ in width. Fig. 4 (a) shows the deposited copper wiring imaged using an optical microscope. Fig. 4(b) shows an SEM image. Copper patterns with 4 to $6 \mu \mathrm{m}$ line spacing could be generated on glass without exfoliation of the deposited copper.

\section{Conclusion}

Direct deposition of smooth and flat copper films on glass without exfoliation could be achieved by introducing a methanol dip, after the sensitization and activation treatment cycle. Furthermore, adhesion strength was improved by heat treatment at $300^{\circ} \mathrm{C}$ under an inert atmosphere. Using this process, copper wiring patterns with a width of 4 to $6 \mu \mathrm{m}$ could be generated by a semi-additive process without exfoliation of deposited copper.

\section{Acknowledgments}

This work was supported by a the CMK Foundation and by a "High-Tech Research Center" project grant for Private Universities a matching fund subsidy from MEXT (Ministry of Education, Culture, Sports, Science and Technology), 2005-2010.

(Received June 18, 2007 ; Accepted August 21, 2007)

\section{References}

1) H. Kawahara ; J. Surface Finish. Soc. Jpn, 44, 186 (1993).

2 ) T. Nishiwaki, H. Honma ; J. JPN. Institute of Electronics Packaging, 4, 128 (2001).

3 ) H. Watanabe, H. Honma ; Plating and Surface Finishing, 82, (1), 60 (1995). 